\title{
8
}

Research Square

\section{Investigating the Feasibility of Implementing a Cloud Seeding Project in Sistan and Baluchestan Province, South East of Iran}

\section{Seyed Arman Hashemi Monfared}

University of Sistan and Baluchestan, Iran

\section{Samaneh Poormohammadi}

National Cloud Seeding Research Center, Iran's Water and Power Resources Development Company (IWPCO), Yazd, Iran

Mehran Fatemi ( $\nabla$ mfatemi1357@gmail.com ) meybod university

\section{Faezeh Rasaei}

University of Sistan and Baluchestan, Iran

Mahmood Khosravi

University of Sistan and Baluchestan, Iran

\section{Research Article}

Keywords: Cloud seeding,Water harvesting ,Fuzzy logic

Posted Date: September 30th, 2021

DOI: https://doi.org/10.21203/rs.3.rs-773173/v1

License: (c) (i) This work is licensed under a Creative Commons Attribution 4.0 International License. Read Full License 


\section{Abstract}

The water shortage is a challenge in many countries around the world. Today, the latest scientific and practical technologies are used to solve the problem of water shortage in arid and semi-arid regions. The optimal use of water resources as well as the use of novel methods of water extraction plays a significant role in alleviating the effects of this crisis. One of the methods used for increasing rainfall and water harvesting from the atmosphere is cloud seeding technology. The first step of this technique involves studying the target area and selecting the appropriate time and place for cloud seeding. The purpose of this study is to investigate the feasibility of cloud seeding in Sistan and Baluchestan province, south east of Iran, for rainmaking. Therefore, using the parameters of precipitation, minimum temperature, relative humidity and cloudy parameter, the status and feasibility for rainmaking in the province were evaluated and suitable months for cloud seeding were determined. Accordingly, December, January, February and March were found to provide suitable conditions for seeding. In order to select suitable places for cloud seeding, zoning maps of precipitation, temperature and relative humidity in selected months as well as the topographic map of the province were prepared by GIS After fuzzyization and integration of these maps, the zoning map of suitable areas for cloud seeding in Sistan and Baluchestan province was drawn to select the most susceptible areas. The area surrounding Khash synoptic station and the southern areas of the province were found to be suitable for cloud seeding.

\section{Introduction}

Precipitation in Iran is less than one third of the average precipitation in the world ) Kazemi \& Ghorbani, 2004). According to water resources experts, one of the most serious crises in the coming decades will be water supply for all the people worldwide. The severe and persistent droughts that have afflicted Iran in recent decades have caused raised concerns in diverse sectors including agriculture, natural resources and especially water resources.

Many studies have explored cloud seeding, determinants of cloud seeding, project implementation, the right time and place of the project, the effect of cloud seeding on different basins, etc. In this research, we used fuzzy logic for proper location of cloud seeding projects in GIS software. The idea of artificial rainfall by cloud seeding was first proposed by Russian scientists in 1932 with the establishment of the Artificial Rain Institute to study the possibility of climate change (NajaFI \& Hosseinzadeh, 2013)

The first cloud seeding test was performed in 1937 in the Netherlands on dry ice. In 1942, a German scientist, Findesen, experimented with cloud seeding. He used sands for cloud seeding, but the result was not successful (Javanmard, 2007). In 1946, Schaefer in his tests in General Electric's laboratory discovered that dry ice could transform cold cloud water droplets (liquid water droplets below zero degrees Celsius) into ice crystals. In an experiment, he injected about $1.5 \mathrm{~kg}$ of dry ice into the stratocumulus clouds by a plane only to observe snowfall after about 5 min under the tested cloud (sin kevich \& et al, 2013). 
As reported by the World Meteorological Organization, more than 51 countries are currently undertaking research on cloud seeding technology. Russia and the United States as two leading countries conducting thorough and extensive research in this field, have a long history of implementation projects about cloud seeding. In Europe, especially countries such as Spain and Italy, projects are underway to overcome the quantitative and qualitative limitations of water resources. France and Austria, among other counties, are attempting to deal with unexpected events such as hail suppression and fog dispersal. Some Middle Eastern countries such as Syria, Jordan, Libya, Morocco, Israel and even countries like China have employed this technology in various ways. In China, the technology was recently used to extinguish largescale fire in Tibetan forest (Javanmard, 2007).

In Iran, cloud seeding research has been carried out for over 20 years by the National Cloud Seeding Center, which is based in Yazd, along with several other projects nationwide. So far, 16 provinces, including Gilan, Mazandaran, Zanjan, West and East Azerbaijan, Ardabil, Kermanshah, Isfahan, Yazd, Kerman, Fars, South Khorasan, Chaharmahal and Bakhtiari, Kohgiluyeh and Boyer Ahmad, Qom and Markazi have joined these projects. Rainmaking projects in Yazd province were conducted not only in the heights of this province, which have huge potentials for seeding, but also in Zagros Mountains, especially the Koohrang heights, which has a crucial role in water supply to Yazd province. The results of these projects have been promising (Portabari, 20117).

Griffith and Solak (2002), in their study on economic feasibility of cloud seeding in the Idaho Basin, concluded that the average cost of feasibility studies relative to the total cost of winter cloud seeding projects was 12\%] (Khalili, 2014). Hunter (2006) examined the rise in water storage through cloud seeding in the Colorado River Basin. According to his research, on average, about one acre of harvesting water per year (or even higher in wet years, and up to 500,000 acres in dry years) can be produced using cloud seeding (Cloud Fertility branch, 2018). Hunter (2007), in a research project funded by the California Energy Commission, reported that cloud seeding was less costly and had a higher cost-benefit ratio than other water-enhancing technologies. Therefore, cloud seeding is an excellent option to help reduce water problems (Hunter, 2007). Javanmard et al. (2007), presented the preliminary results of cloud seeding location studies for rainmaking in Iran. The process was in compliance with report No. 3 of the World Meteorological Organization's project for rainmaking. The results of their study suggested that the possibility of cloud seeding is higher in the northwest, north and northeast of Iran with a decreasing trend from north to center and south and east (Javanmard, 2007). Dorfa et al. (2013) demonstrated how salt powder distribution works on cloud models. The experimental results showed the positive effects of salt powder on climate adjustment operations and precipitation. The dispersion of salt powders in clouds leads to the formation of large cloud droplets and the expansion of the droplet spectrum. This is a positive factor for stimulating coagulation processes and precipitation (Drofa, 2013). According to a 2013 study by Najafi and Hosseinzadeh, the injection of liquid carbon dioxide in the cumulonimbus cloud in the point position increased the quantity and intensity of rainfall, which was greater than the linear and temporal modes. If the cloud spread was about half a kilometer and an altitude of $10.5 \mathrm{~km}$, this operation would be more effective (Najafi,\& Hosseinzadeh, 2013). Sin Kevich et al. (2013) analyzed three cases of cumulonimbus cloud seeding in Saudi Arabia. The results revealed huge potentials of cumulonimbus 
clouds for seeding to stimulate precipitation (Sin'kevich, 2013). Poormohammadi and Golkar (2011) conducted a feasibility study of cloud seeding in Golestan province. First, using climatic parameters of temperature, precipitation, wind speed, cloudiness, number of frost days and fog in synoptic stations of Golestan province, they determined the appropriate times for cloud seeding in the basin. The results of this study illustrated that October, November, December, February, March and April are suitable for cloud seeding. Also, to identify appropriate places for cloud seeding, they drew a map of waterways, dams, land use, etc. Using the model data, they prepared isothermal maps of the upper atmosphere in the months designated for cloud seeding to investigate the possibility of aerial and ground seeding in the region (Pourmohammadi \& Golkar, 2011). Pourmohammadi and Khalili (2013) investigated the possibility of cloud seeding in Hamadan province by addressing the climatic parameters of temperature, precipitation, wind speed, number of frost days and fog in six stations of Hamadan province. In this way, appropriate cloud seeding times in the basin were determined. In the next step, isothermal, wind speed and direction maps were designed for the upper atmosphere during the months designated for cloud seeding in order to analyze the feasibility of this project in the province. The results of this study revealed that November, December, January, February, March and April are appropriate for cloud seeding (Pourmohammadi \& Khalili, 2013). Poor Mohammadi and Golkar (2016) evaluated the effect of cloud seeding on rainmaking and increasing surface and groundwater resources in the catchments of East Azerbaijan province in the water year of 2011-2012. The findings of their study suggested that cloud seeding in this basin prompted 19\% surge in rainfall, with a subsequent rise of 97.6 and 22.04 million cubic meters in the production of surface and groundwater resources, respectively ((Pourmohammadi \& Golkar, 2016). Kazemi and Ghorbani (2015) utilized different interpolation methods including inverse distance weighting, normal kriging, radial base function, etc. for estimation and zoning of rainfall variables in Aqqala agricultural lands. The results of this study showed that the local polynomial method, compared to other methods, can offer a more accurate estimate of climatic variables and that the spherical method was the best fitted model is (Kazemi \& Ghorbani, 2004). Naum and Tsanis (2004) introduced the best model for estimating frequency maps of exponential and general models in Switzerland [42]. Coulibaly and Baker (2007) recommended the conventional kriging method, which involved comparing different statistical methods for internalizing annual, monthly, and daily rainfall (Coulibaly \& Becker, 2007). Zhang and Srinivasan (2009), by examining kriging family methods Inverse Distance Weighted (IDW), showed that the kriging method with an external trend yielded the lowest errors among other methods (Zhang \& Srinivasan, 2009).

The goal of this study is to investigate the feasibility of implementing a cloud seeding project in Sistan and Baluchestan province. For this purpose, the appropriate time and place of the project to increase water extraction in the province are determined.

\section{Methodology \\ 2.1 Study area}


Sistan and Baluchestan province, with an area of about $181758 \mathrm{~km} 2$, is located between 25 degrees and 3 minutes and 31 degrees and 27 minutes north latitude and between 58 degrees and 50 minutes and 63 degrees and 21 minutes east of the Greenwich meridian.

Sistan and Baluchestan province comprises two regions of Sistan and Baluchestan, which consists of the cities of Zahedan, Khash, Saravan, Iranshahr, Nikshahr, Chabahar, Sarbaz, Konarak, Delgan, Zaboli, Sib and Soran, Qasr Ghand and Fanuj. Sistan region also encompasses the cities of Zabol, Zahak, Nimroz, Hamoon and Helmand. Figure $4-1$ shows the study area.

This vast province shares borders with Pakistan and Afghanistan in the east, and has a water border with the Oman Sea that extends $270 \mathrm{~km}$ in the south. It is also surrounded by Khorasan province in the north and northwest, and Kerman and Hormozgan provinces in the west.

\subsection{Research Methods}

In the first step of the research, basic information such as topographic characteristics of the region, climate and catchment conditions in various regions, etc. are collected from relevant organizations. In the next step, Excel and SPSS software are used for statistical analysis in order to determine the appropriate time for cloud seeding. To identify suitable areas and places for project implementation, the fuzzy method was used in GIS software.

This section describes the zoning of Sistan and Baluchestan province in the designated months of cloud seeding using fuzzy method in GIS environment. Thus, after selecting parameters that influence the determination of operational areas such as precipitation, relative humidity, etc. and parameter weighting, a raster and fuzzy map were designed for each parameter and finally the zoning of suitable sites for cloud seeding in designated months was carried out.

Figure 2 shows the flowchart of this research, research steps, required data and methods used in GIS software.

\subsection{Climatic parameters of study}

Data derived from synoptic stations of the province was used to determine the appropriate time for cloud seeding. After reviewing the statistical period of each station, the 16-year statistical period from 2001 to 2017 was appointed as a common statistical period. The characteristics of synoptic stations in Sistan and Baluchestan province are shown in Table 1. 
Table 1

Specifications of synoptic stations in Sistan and

Baluchestan province

\begin{tabular}{|llll|}
\hline Station & Longitude & Latitude & Station height $(\mathrm{m})$ \\
\hline Chabahar & 60.5 & 25.23 & 8 \\
\hline Iranshahr & 60.7 & 27.2 & 591.1 \\
\hline Khash & 61.2 & 28.21 & 1394 \\
\hline mirjave & 61.43 & 29.01 & 836 \\
\hline Nikshahr & 60.21 & 26.23 & 510 \\
\hline Saravan & 62.33 & 27.33 & 1195 \\
\hline Zabol & 61.48 & 31.21 & 489.2 \\
\hline zahak & 61.68 & 30.9 & 495 \\
\hline zahedan & 60.88 & 29.46 & 1369.9 \\
\hline
\end{tabular}

To compensate for missing data, we used the monthly regression method to reconstruct data between the nearest station and the desired station. Mirjavah and Nikshahr stations needed data reconstruction; Since the closest stations to Mirjaveh and Nikshahr stations are Zahedan and Iranshahr stations, respectively, the data obtained from these two stations were used reconstruct regression function in SPSS.

For the implementation of rainfall enhancement projects, an area should have necessary potentials for the execution of cloud seeding projects in that area. Thus, the criteria set by the World Meteorological Organization (precipitation enhancement program) were used to determine the parameters affecting the successful implementation of the project. These parameters include the average relative humidity, temperature, precipitation and topographic factor. In fact, each of these parameters contain several criteria in the report on increasing rainwater harvesting. For example, the average relative humidity is directly related to the water parameter of cloud rainfall.

Temperature is also one of the basic parameters related to precipitation and cloud formation, which determines the type of fertilization materials and cloud fertility method.

One of the essential factors for determining the proper place of cloud seeding is the analysis of the rainfall status in that area. The main goal of cloud seeding, especially in arid and semi-arid regions, is to increase rainfall in order to alleviate water shortage and drought in these areas. Abundant rainfall in an area may indicate that the -suitable cloud systems to precipitation is at work in that area.

Therefore, temperature, relative humidity and precipitation maps of the selected months in the statistical period of 2001-2007 should be taken into consideration. 
In order to select the best interpolation method, zoning maps were compared and cross-validated using geostatistical methods. Figure 2 shows a comparison of circular ordinary kriging and spherical ordinary kriging for the precipitation zoning.

This Figure shows the two methods of interpolation with toxicovariogram and linear regression prediction of maps. At the bottom, mean, root mean square, and standardized mean are depicted. The standardized toot mean square and the standard mean error along with the numerical values of each box related to the aforesaid methods are shown. According to the figure, it can be inferred that the root mean error of the zoning map by the conventional circular kriging method (on the right) is lower than the numerical value in the conventional spherical kriging method. A lower value indicates lower evaluation error. Other values obtained from the cross-evaluation of both maps indicate that the conventional circular kriging method is more desirable. Therefore, the zoning map related to this method was selected as a promising candidate for the interpolation method.

\subsection{Mapping Areas Suitable for Cloud Seeding Using Fuzzy Method}

It is necessary to prepare a map of each selected parameter in the range of 0 to 1 . In this research, the degree of each parameter's membership is defined using a linear function.

In the following, the membership function of all four parameters was defined based on expert opinions, with respect to the range of values in each map and regional characteristics.

As for temperature, given the negative correlation between temperature and precipitation, and the fact that the temperature range varied from 10 to $22^{\circ} \mathrm{C}$, values less than 16 received a score of 1 , values greater than 19 received a score of 0 , and values in the range of 16 and 19 received a score between 0 and 1.

\section{Results}

Figure 3 shows standardized fuzzy maps for the parameters of mean relative humidity, precipitation, temperature, and topography.

Figure 4 is shown of the standardized fuzzy of precipitation, relative humidity, DEM and temperature maps. The value of each pixel is between 0 to 1 with zero indicating the lowest priority for cloud seeding and one revealing the highest priority. As can be seen, the central and southern parts of the province are more desirable with respect to only one precipitation parameter in for the fertilization of the clouds.

In Figure 4, the dark parts that cover most of the province are suitable for cloud seeding in terms of temperature parameter.

Finally, after extracting all information layers in the positioning process, various information layers are merged under an overlay in the GIS system. The weight of each layer was determined according to the 
Global Meteorological Report (PEP) score. Table 3-4 shows the weight of parameters used to determine the suitable areas for seeding. According to this method, precipitation (33\%), average relative humidity (33\%), topography $(12 \%)$ and temperature $(22 \%)$ were calculated by weight.

Finally, after extracting all information layers in the positioning process, various information layers in the GIS system were merged under an overlay. The weight of each layer was determined according to the Global Meteorological Report (PEP) score. Table 2 shows the weight of parameters used to determine the fertile areas for the clouds. According to the method, precipitation (33\%), average relative humidity (33\%), topography $(12 \%)$ and temperature $(22 \%)$ were computed by weight.

Table 2

The weight of parameters used to determine the fertile areas of the clouds

\begin{tabular}{|ll|}
\hline Parameters name & Parameter weight \\
\hline Relative humidity & 0.33 \\
\hline Rainfall & 0.33 \\
\hline Temperature & 0.22 \\
\hline DEM & 0.12 \\
\hline
\end{tabular}

Precipitation and relative humidity are the most crucial parameters in determining suitable areas. As mentioned before, the higher frequency of rainfall in an area may indicate a cloud system suitable for rainfall in this area.

Figure 5 shows the result of zoning in areas suitable for cloud seeding or desirable areas in Sistan and Baluchestan province (the fuzzy model's output). This map merges the membership function maps of temperature, precipitation, relative humidity and topography parameters.

\subsection{Determining monthly cloud seeding priorities}

From a climatological viewpoint, the temporal distribution of precipitation is highly important in feasibility analysis of rainfall plans, for these plans must be conducted at the most appropriate time from an economic perspective.

According to the standard charts and indicators set by the World Meteorological Organization (WMO), the months in which relative humidity is more than $35 \%$, minimum temperature is between 0 and $5{ }^{\circ} \mathrm{C}$ and rainfall is greater than $10 \mathrm{~mm}$ are suitable for seeding. Clouds need to be selected in the desired area.

Since cloud seeding is only possible when the sky is entirely cloudy, it is worth noting that there are 4 full cloudy days in the selected months and 3 days with more than $5 \mathrm{~mm}$ rainfall in the month. 
Therefore, for a more accurate selection, we used a program with the conditions described in MATLAB

Table 3

Conditions required for selecting the appropriate time for cloud seeding

\begin{tabular}{|llll|}
\hline Parameters & Relative humidity & Minimum temperature & Rainfall \\
condition & $35 \%<$ & $0-5^{\circ} \mathrm{C}$ & $<10 \mathrm{~mm}$ \\
\hline
\end{tabular}

It is worth mentioning that sub-zero temperatures leads to frost, which may hinder the take-off of the aircraft for fertilizing the clouds.

Therefore, according to the data obtained in this study, the highest percentage of rainfall frequency, relative humidity and cloud cover was observed in December, January, February, March and April in the region. As far as the suitable conditions for cloud seeding are concern, March was the most suitable month for cloud seeding in the province, followed by February, December and January, respectively. There months were the best time to implement the rainmaking project in this field.

\subsection{Determining spatial priorities of cloud seeding in the province}

Figure 6 shows the classification of areas suitable for cloud seeding in Sistan and Baluchestan province. According to the map extracted from the fuzzy method, the province was divided into three regions in terms of cloud seeding.

In the south of the province, the relative humidity is high due to its proximity to the sea, and the rainfall in this area surpasses other parts of the province. As mentioned earlier, the relative humidity and precipitation parameters are two critical parameters in selecting appropriate sites for cloud seeding. Due to the effect of these two parameters, the selected region was found to be suitable for cloud seeding.

By comparing the map of potentially suitable areas with the maps of precipitation, temperature, topography, etc., it can be seen that in the basin surrounding the Khash synoptic station, the topographic and temperature factors have contributed to the suitability of this area for cloud seeding.

In light of the above map, 3 zones with different potentials could be identified:

First priority - suitable lands (value 0 / 45-668 / 0)

Second priority - moderate lands (value 0.3-0.3)

Third priority - relatively unsuitable lands (value $0.17-0.3$ )

Table 4 
Group specifications of cloud seeding priorities

\begin{tabular}{|lll|}
\hline Priority & Description of features & Area (percent) \\
\hline 1 & With high potentials & $13 \%$ \\
\hline 2 & with moderate potentials & $54 \%$ \\
\hline 3 & Relatively inappropriate & $33 \%$ \\
\hline
\end{tabular}

It should be noted that the feasibility analysis of cloud seeding in an area is based on its current situation. In other words, due to the change of climatic variables, the feasibility study related to previous conditions may be invalid for the future.

\section{Declarations}

\section{Conflict of Interest}

The authors of this manuscript declare that there is no conflict of interest.

\section{Funding Statement}

This research has not been supported financially by any university or any research institutes or rganization.

\section{Author's Contribution}

S. Poormohammadi, S.A. Hashemi Monfared and M. Khosravi designed the study. F. Rasaei and S. Poormohammadi did most of the data retrieval and the geostatistical analyses and map generations. M. Fatemi and S. Poormohammadi wrote the first draft of the manuscript and M. Fatemi did review and editing supervision. All authors contributed to the final draft.

\section{Availability of data and material}

All of the needed data for this research (including rainfall, mean temperature and humidity data as well as digital elevation model and basin border shape files) have been prepared from the Iran's National Meteorological Organization and Iran's National Cartographic Center (NCC), which are freely available and can be prepared and accessed easily for the domestic research purposes. 


\section{Code availability}

There has been used no computational code for fulfilment of the present research steps.

\section{Ethics approval}

All the authors mentioned in the manuscript have agreed for authorship and ethically approved it.

\section{Consent to participate}

All the authors mentioned in the manuscript have given consent to participate in this manuscript.

\section{Consent for publication}

All the authors mentioned in the manuscript have given consent for submission and subsequent publication of the manuscript in this journal.

\section{References}

1. Kazemi H, Kh G., (2004) Evaluation of different interpolation methods for estimating and zoning precipitation variables in agricultural lands of Aq Qala city for dryland cultivation of autumn grains, Journal of Soil and Water Conservation Research, Volume 22, Number 4 1394.Naoum, S., Tsanis IK, Ranking spatial interpolation techniques using a GIS-Based DSS, Global nest 6, pp. 1-20

2. Coulibaly M, Becker S (2007) Spatial interpolation of annual precipitation in Africa- comparison and evaluation of methods. International water resources association 3(23):494-502

3. Zhang X, Srinivasan R (2009) GIS-Based spatial precipitation estimation: A comparison of geostatistical approaches. Journal of the American water resources association (JAWRA) 45(4):894-906

4. Poormohammadi S, Golkar F (2011) Investigation of the possibility of cloud seeding in Golestan province to mitigate the effects of climate change, First National Conference on Meteorology and Agricultural Water Management, Campus of Agriculture and Natural Resources, University of Tehran

5. Poormohammadi S, Khalili M (2013) Investigation of the possibility of cloud seeding using meteorological parameters (Case study: Hamadan province), First National Conference on Meteorology of Iran, Kerman University of Industrial and Advanced Technology

6. Poormohammadi S, Golkar F (2016) The effect of cloud seeding technology on surface and groundwater resources for sustainable management of catchments (East Azerbaijan province), Sixth National Conference on Water Resources Management, University of Kurdistan 
7. Griffith DA, Solak ME (2002) Economic feasibility assessment of winter cloud seeding in the boise river drainage IDAHO. Journal of weather modification 34:39-46

8. Hunter SM (2006) Potential water augmentation from cloud seeding in the Colorado River basin. Journal of weather modification

9. Hunter SM (2007) Optimizing cloud seeding for water and energy in California. Califonia Energy Commission

10. Javanmard s (2007) Bodagh jamali, J.,Noorian, A.M., Preliminary results of site selection study for cloud seeding in order for precipitation enhancement in I.R. of Iran, Journal of weather modification, Vol. 39, pp. 87-95

11. Drofa AS, Eran'kov VG, Ivanor VN, Shilin AG, Iskevich GF (2013) Experimental investigation of the effect of cloud-medium modification by salt powders. Atmospheric Oceanic physics 49(3):298-306

12. Najafı M, Mohammad-Hosseinzadeh F (2013) Numerical Simulation of deep convective cloud seeding using liquid carbon dioxide. International Journal of environmental science technology 10(4):665-676

13. Sin'kevich AA, Krauss TW, Ghulam AS, Kurov AB (2013) Investigation of High-Depth Cumulonimbus cloud characteristics after seeding to increase precipitation. Russian meteorological hydrology 38:No. 9

14. Final Report on Cloud Fertility Feasibility in Ardabil Province (2010) Ministry of Energy. Water Research Institute, National Center for Cloud Fertility Research and Studies

15. Portabari MR (2017) Investigation of Environmental Impacts of Cloud Fertilization, Fourth International Conference on Environmental Planning and Management, Tehran

16. Sarnobeh S, Sarnobeh P, Vasei Chaharmahali S (2016) How to perform cloud fertility to moderate the climate of arid regions of Iran, the first national conference on water management with the approach of optimal water consumption in agriculture, Hamadan

17. Khalili M (2014) Project Report on Feasibility Studies and Implementation of Fertilization Identification Flights on Cloud Systems in Hamadan Province, Ministry of Energy. Water Research Institute, National Center for Cloud Fertility Research and Studies

18. Cloud Fertility A Branch of Climate Modification Technologies, Ministry of Energy, (2018) Water Research Institute, National Center for Cloud Fertility

\section{Figures}




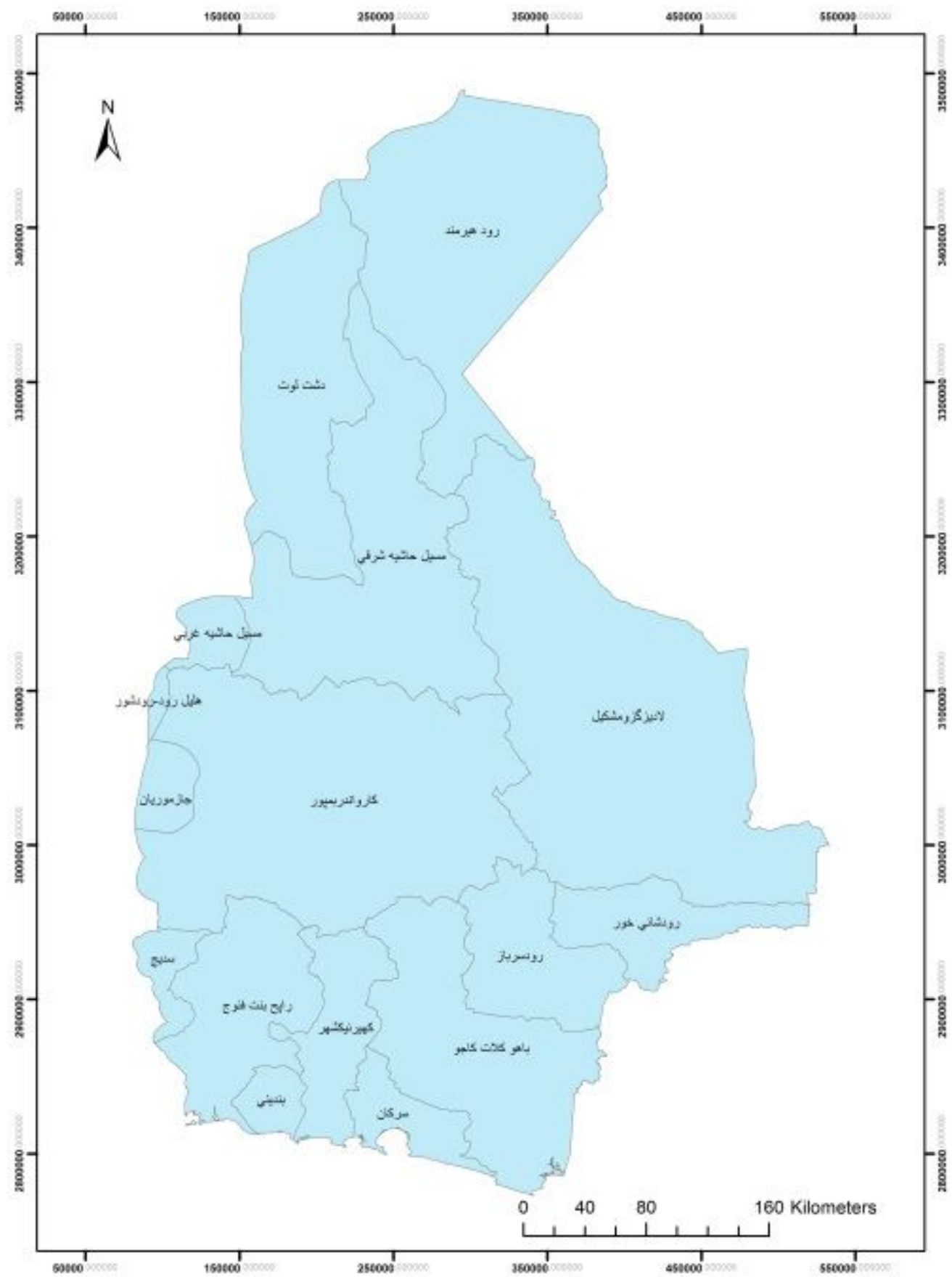

Figure 1

Sistan and Baluchestan province and its sub-basins 


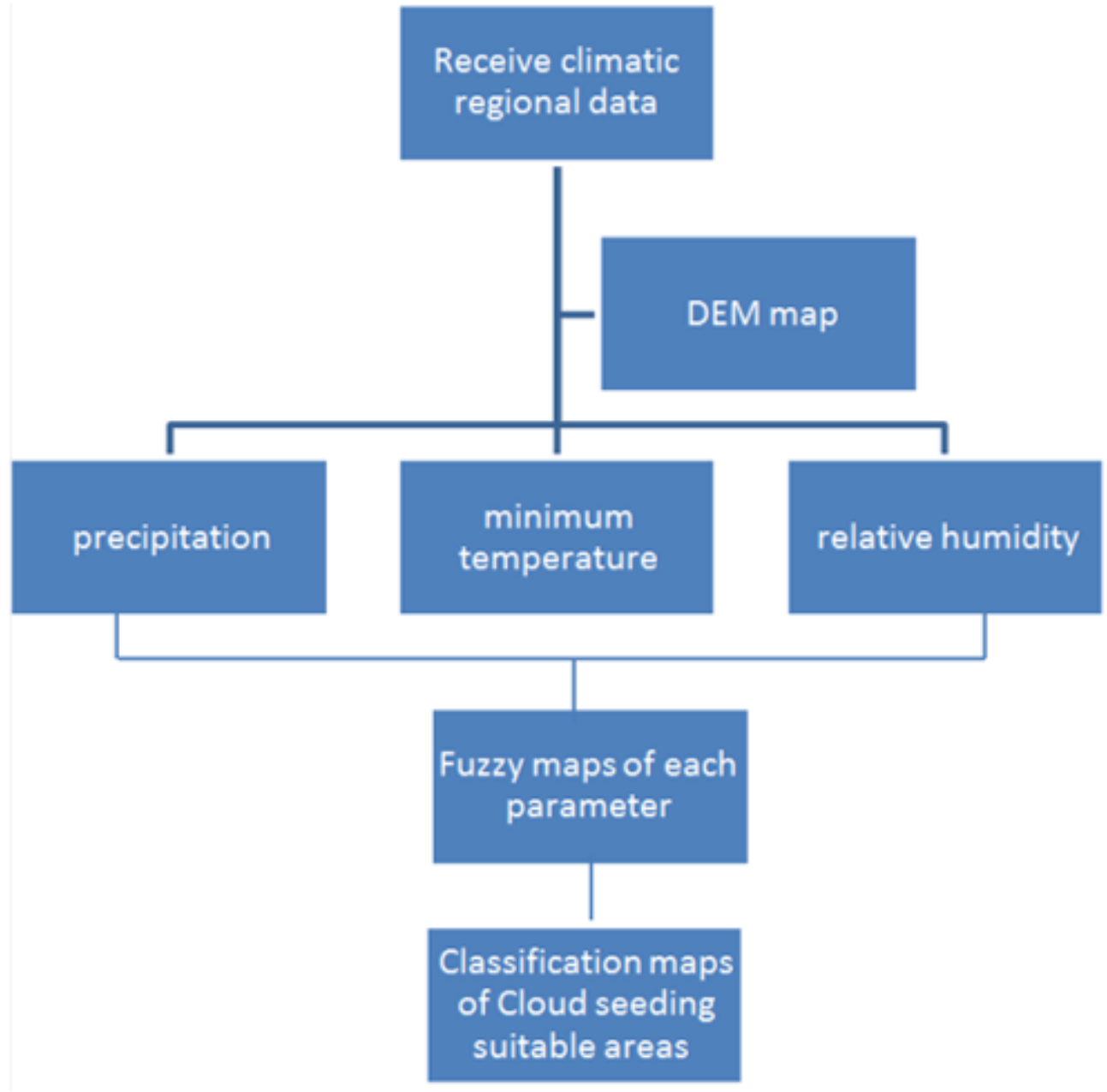

Figure 2

Flowchart of the research 


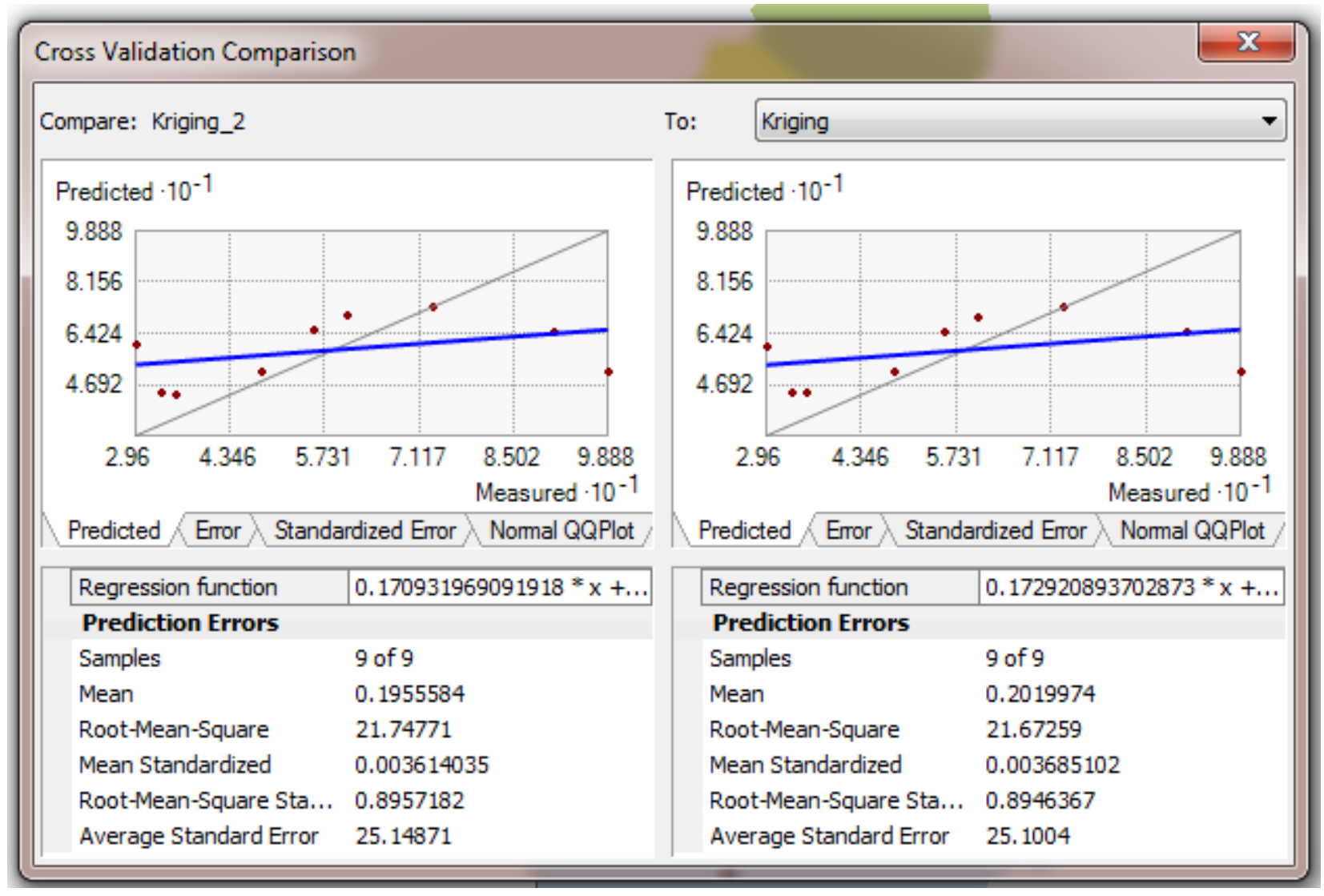

Figure 3

Evaluation of two maps using ordinary circular kriging and ordinary spherical kriging 
A) Medium temperature

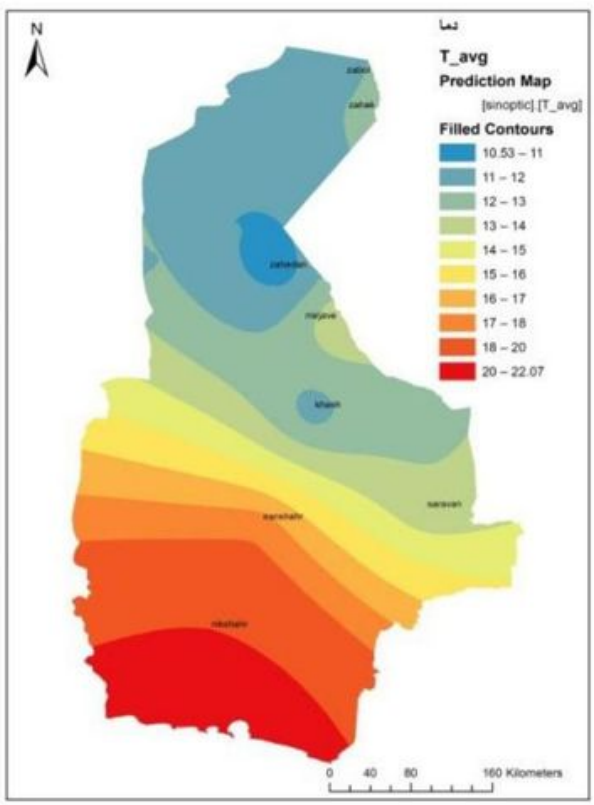

C) Topography

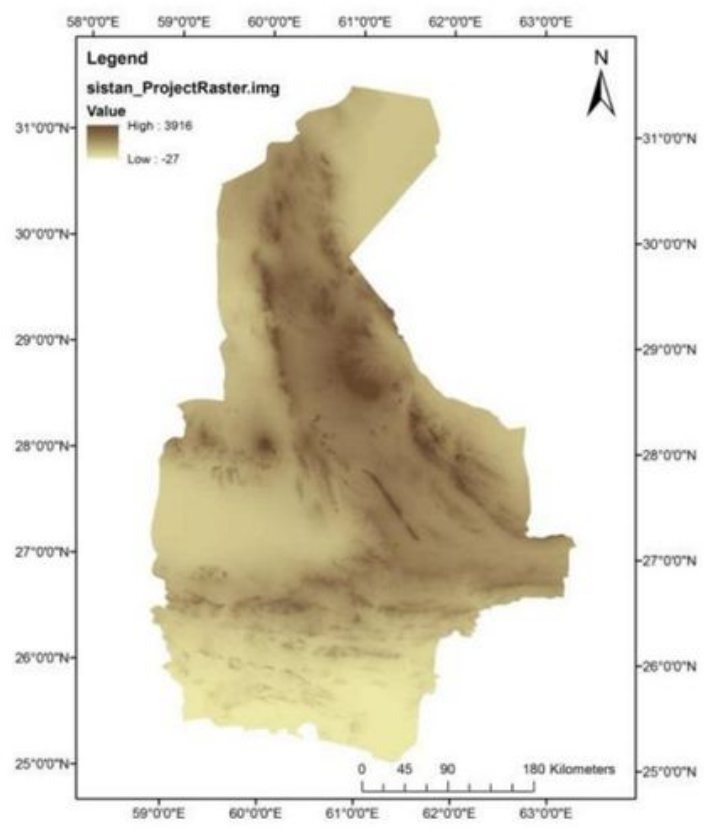

B) Relative humidity

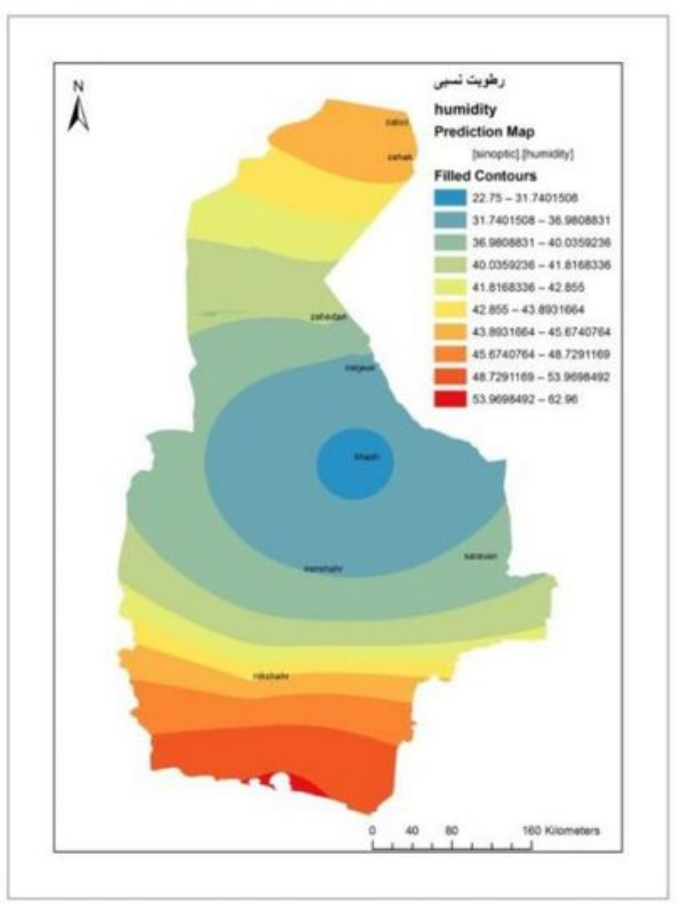

D) Rainfall

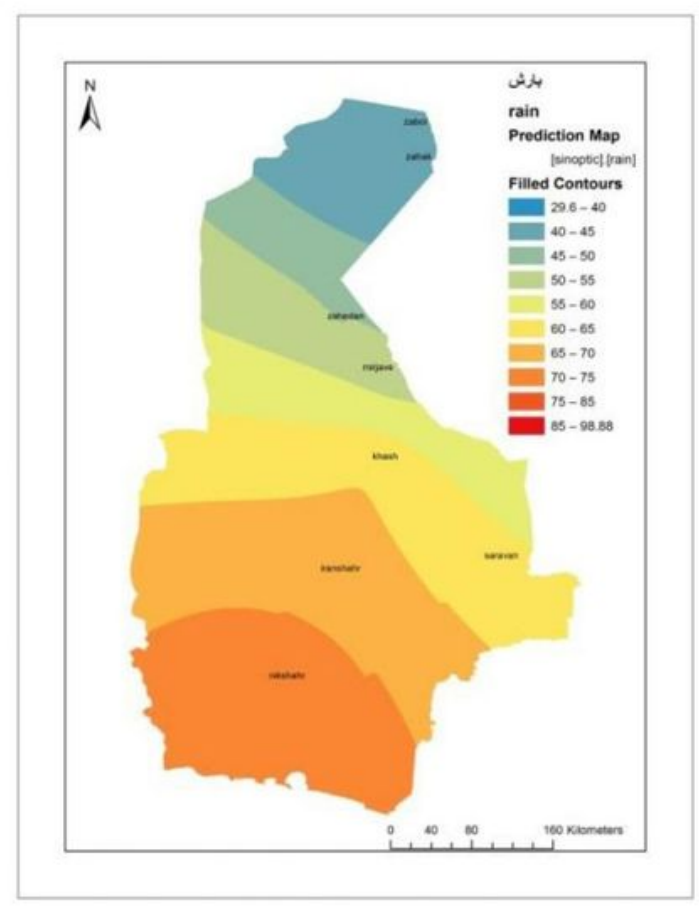

\section{Figure 4}

shows the standardized topographic fuzzy map in which brown areas indicate topographic factors. 
A) Rainfall fuzzy map

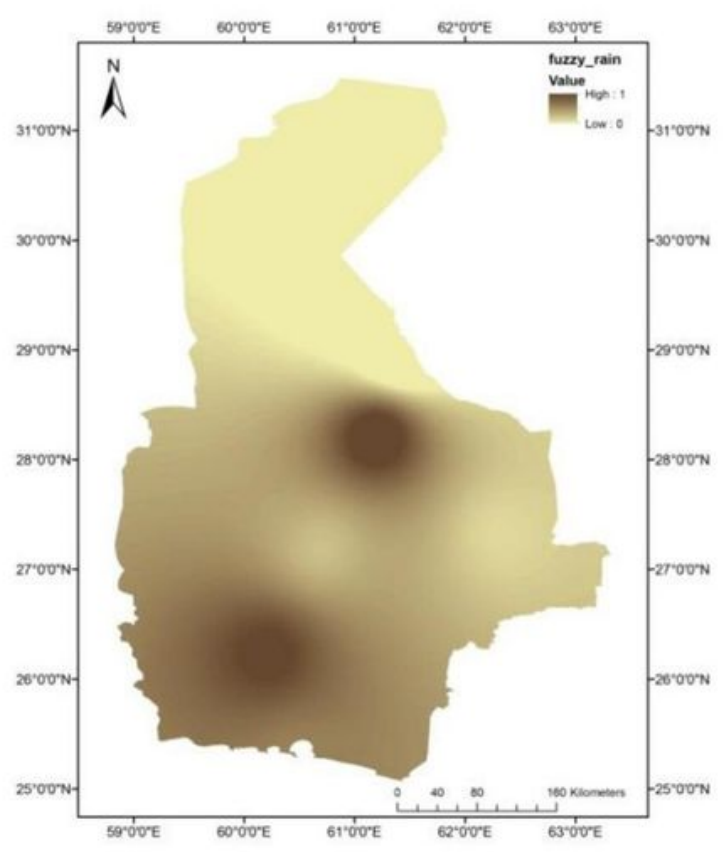

C) DEM fuzzy map

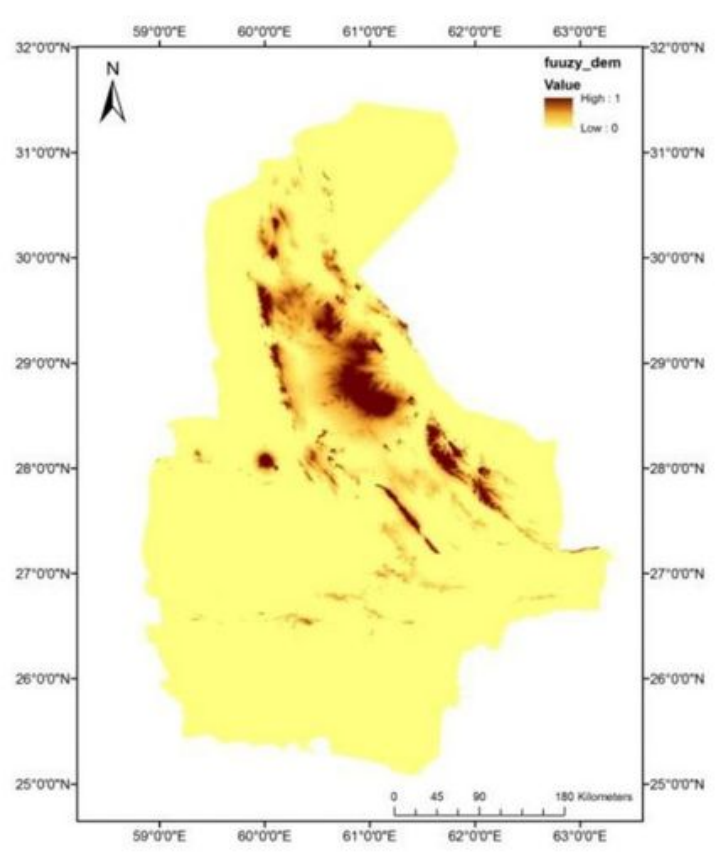

B) Fuzzy map of relative humidity

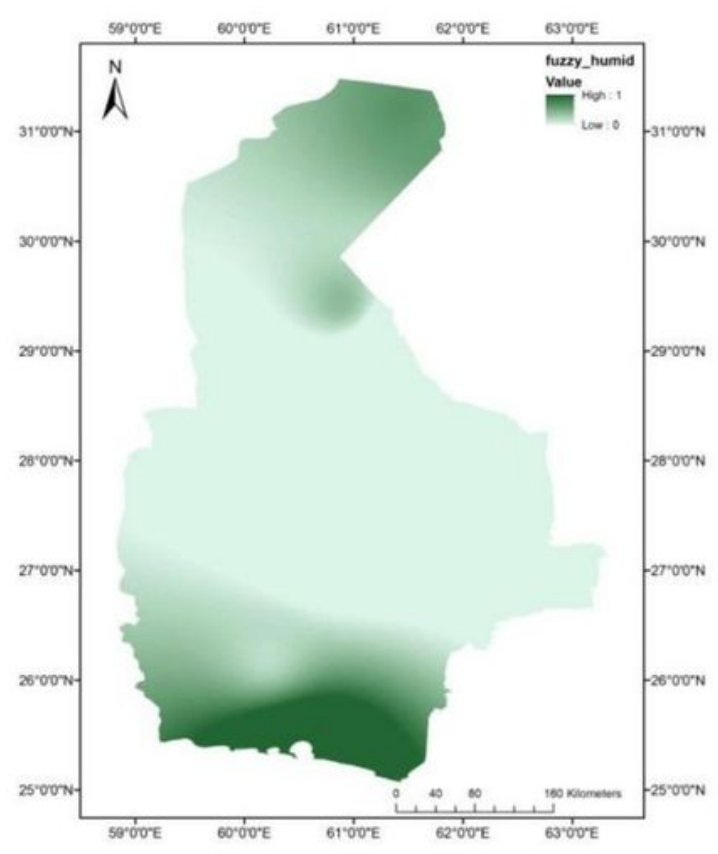

D) Temperature fuzzy map

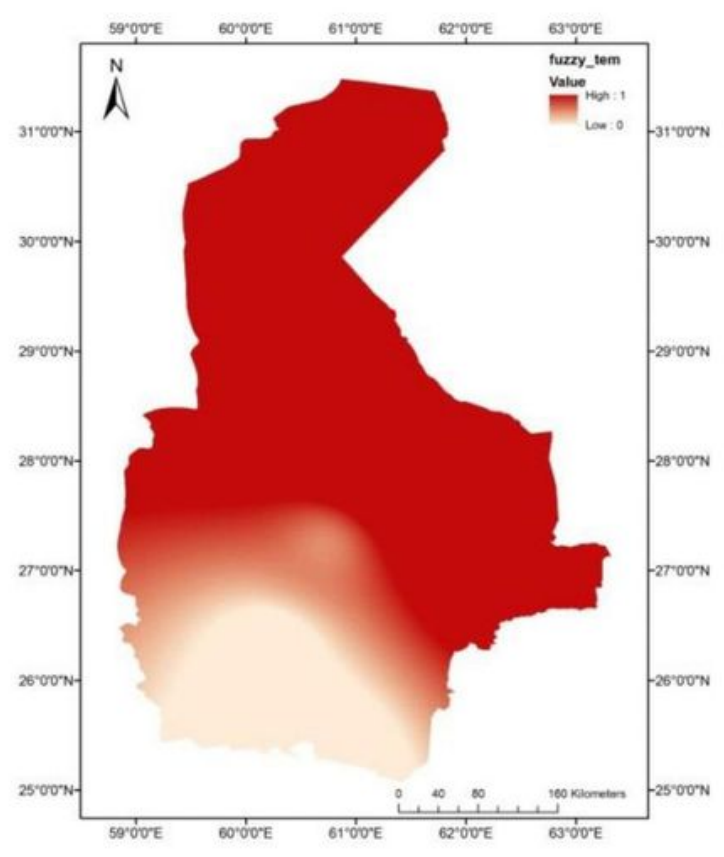

\section{Figure 5}

Fuzzy map of four parameters 


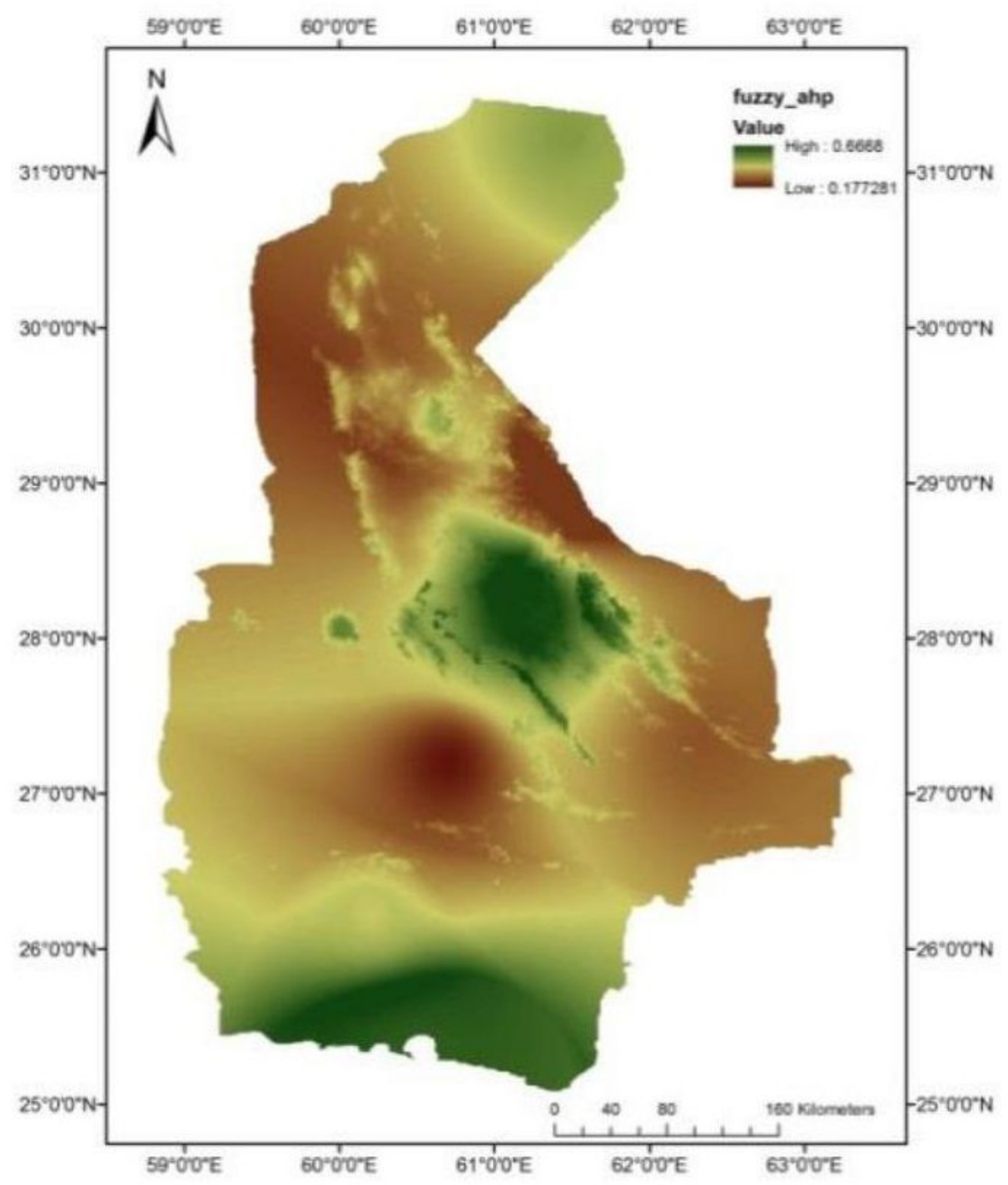

Figure 6

Zoning of fertile areas in Sistan and Baluchestan province 


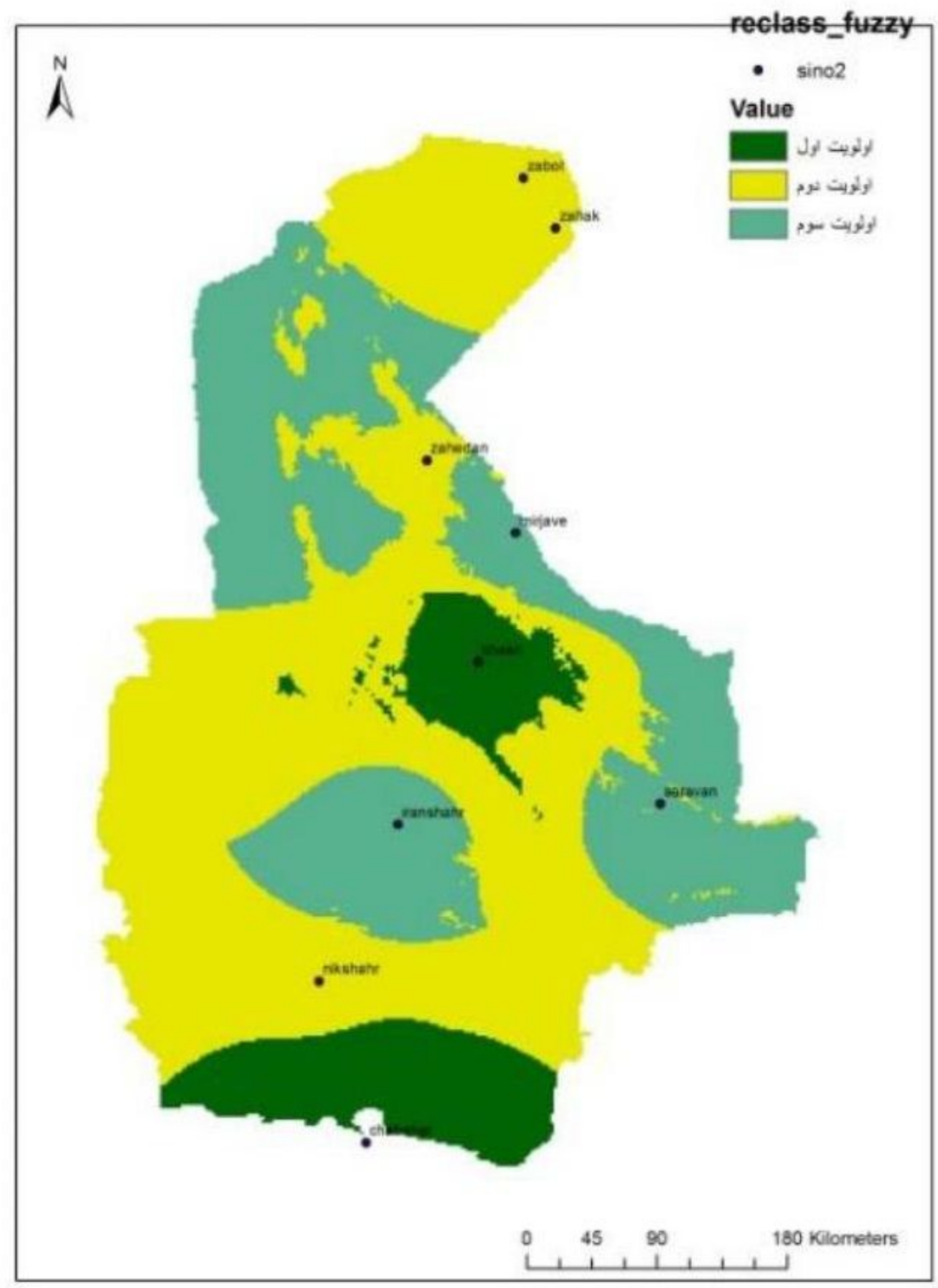

Figure 7

Classification of areas suitable for cloud seeding in Sistan and Baluchestan province 